\title{
Unresectable Ectopic Hepatocellular Carcinoma Treated with Sorafenib
}

\author{
Yi-Ling Ko ${ }^{a}$ Kazuhide Takata ${ }^{a}$ Takashi Tanaka $^{a}$ Jun Ohishi ${ }^{\text {b, c }}$ \\ Morishige Takeshita $^{d}$ Ryo Yamauchi ${ }^{a}$ Hiromi Fukuda ${ }^{a}$ \\ Takashi Miyayama $^{a}$ Yotaro Uchida ${ }^{a}$ Keiji Yokoyama ${ }^{a}$ \\ Daisuke Morihara $^{a}$ Yasuaki Takeyama ${ }^{a}$ Satoshi Shakado $^{a}$ \\ Shotaro Sakisaka ${ }^{a}$ Fumihito Hirai ${ }^{a}$
}

aDepartment of Gastroenterology and Medicine, Faculty of Medicine, Fukuoka University, Fukuoka, Japan; bDivision of Gastroenterological Surgery, Faculty of Medicine, Fukuoka University, Fukuoka, Japan; 'Division of Gastroenterological Surgery, Hakujuji Hospital, Fukuoka, Japan; dDepartment of Pathology, Faculty of Medicine, Fukuoka University,

Fukuoka, Japan

\section{Keywords}

Ectopic HCC · Sorafenib · Tyrosine kinase inhibitor

\begin{abstract}
Ectopic hepatocellular carcinoma (HCC) is a rare malignancy, which manifests similar morphology and immunohistochemistry to intrahepatic HCC. Herein, we report a case of ectopic HCC in a 73-year-old male. The patient presented to our hospital with gradually progressing right lower abdominal pain, and enhanced computed tomography revealed multiple nodules in the peritoneum without intrahepatic mass. A diagnostic laparoscopy was performed, and the final pathology result confirmed that it was HCC. Additional laboratory tests showed elevated serum alpha-fetoprotein and protein induced by vitamin K absence-II (PIVKA-II) levels, suggesting our diagnosis. The patient received sorafenib, a tyrosine kinase inhibitor (TKI), for unresectable ectopic HCC. However, the tumor progressed, and because of tarry stools and hemorrhagic anemia, sorafenib was ceased after 7 months of therapy. One month after the cessation of sorafenib, the PIVKA-II level increased abruptly, and the patient died 1 year after diagnosis.
\end{abstract}




\section{Case Reports in Gastroenterology}

Case Rep Gastroenterol 2020;14:226-233

DOI: $10.1159 / 000506929$

(c) 2020 The Author(s). Published by S. Karger AG, Base www.karger.com/crg

Ko et al.: Ectopic HCC Treated with Sorafenib

The effective treatment for unresectable ectopic HCC is still unknown. Additional cases should be accumulated to determine the effect of TKI on ectopic HCC.

(C) 2020 The Author(s)

Published by S. Karger AG, Basel

\section{Introduction}

Ectopic livers are islands of normal liver parenchyma separated from the mother liver [1]. Their incidence is 0.23 and $0.47 \%$ in the largest autopsy and laparoscopic series, respectively [2]. Hepatocellular carcinoma (HCC) arising from ectopic liver tissue is rare, and the risk factors for HCC arising in the mother liver such as hepatitis B virus or hepatitis C virus infection, alcohol abuse, and cirrhosis are less relevant to ectopic HCC [2].

Ectopic HCC is often discovered by incidental imaging, and the diagnosis is difficult to confirm preoperatively [1]. Herein, we report a case of unresectable ectopic HCC, treated with sorafenib, a tyrosine kinase inhibitor (TKI).

\section{Case Presentation}

A 73-year-old male was referred to our hospital for gradually progressing right lower abdominal pain. His past history included prostate carcinoma with bone metastasis at 60 years of age, and type 2 diabetes mellitus diagnosed at 62 years of age with poor control of the hemoglobin A1c (HbA1c) level measuring 8.0\%. Family history revealed that his siblings had type 2 diabetes mellitus and his uncle had gastric cancer. He had a personal history of social alcohol drinking of less than 60 g per day, and smoking of 25 cigarettes per day for 25 years but had quit for over 20 years. Current medications included bicalutamide for prostate carcinoma, metformin, glimepiride and sitagliptin for type 2 diabetes mellitus, and ramelteon, suvorexant, and zolpidem for insomnia.

The vital signs of the patient were stable. Right lower abdominal tenderness was noted without abdominal guarding or rebound tenderness. Laboratory data revealed abnormal liver enzyme levels, and serologic tests were negative for hepatitis B and C (Table 1). Esophagogastroduodenoscopy and total colonoscopy revealed no abnormalities except for cecal diverticulum. Ultrasonography revealed a 5.5-cm tumor near the ileocecal junction, while contrast-enhanced computed tomography (CT), and positron emission tomography-CT showed multiple nodules with cystic lesions in the peritoneum, suggesting peritoneal dissemination in addition to the main tumor (Fig. 1a-d).

A diagnostic laparoscopy was performed, and a tumor extending from the right lateral abdominal wall with irregular focal protrusion was noted. Multiple brown-colored nodules on the greater omentum, one nodule on the small intestines, and one nodule on the anterior abdominal wall, sharing the same gross appearance, were also noted. Histological examination revealed tumor cells with a relatively abundant cytoplasm and a large area of hyperplasia in a palisading pattern (Fig. 2). Small bile droplets were detected in the tumor cells by bile stain. Immunohistochemical staining showed that the tumor cells were positive for alpha methyl acyl coenzyme A racemase, cytokine (CK) 8, alpha-fetoprotein (AFP), and protein induced by 


\section{Case Reports in Gastroenterology}

Case Rep Gastroenterol 2020;14:226-233

DOI: $10.1159 / 000506929$

(c) 2020 The Author(s). Published by S. Karger AG, Base www.karger.com/crg

Ko et al.: Ectopic HCC Treated with Sorafenib

vitamin K absence or antagonist-II (PIVKA-II), and weakly positive for anti-hepatocyte, CK 18, heat shock protein 70, and glypican 3 (Fig. 2). According to the abovementioned results, HCC of the abdominal wall with peritoneal seeding was diagnosed. Because no lesion of the mother liver was discovered by abdominal sonography, CT, or magnetic resonance imaging, a diagnosis of ectopic HCC was determined. Additional laboratory tests showed an elevated serum AFP level and PIVKA-II level, and liver biopsy revealed slight inflammatory infiltrates in the portal area with mild to moderate fibrosis and slight fatty change in liver cells.

The patient received $400 \mathrm{mg}$ of sorafenib per day for ectopic HCC. Two months later, CT imaging showed a significant increase in the tumor size, and blood tests showed increased levels of serum AFP and PIVKA-II. During the follow-up, the tumor response was classified as progressive disease according to response evaluation criteria in solid tumors (RECIST) version 1.1 and modified RECIST (mRECIST). However, the patient showed strong willingness to continue the treatment. Four months later, hematochezia and grade 3 anemia were noticed, according to the categorization of common terminology criteria for adverse events (CTCAE) version 5.0. Contrast-enhanced abdominal CT for evaluation of gastrointestinal bleeding showed tumor progression in the small intestines, which was considered the cause of bloody stools and progressive anemia. However, since the patient refused further survey of the lesions, conservative treatment with blood transfusion was performed. In addition, the bleeding complication was also considered one of the adverse effects of sorafenib, by which the blockade of vascular endothelial growth factor caused endothelial disruption and consequent bleeding events. As a result, the dosage of sorafenib was modified to $200 \mathrm{mg}$ per day. In spite of that, sorafenib was eventually ceased 7 months after the start of treatment because of persistent diarrhea and progressive anemia. One month after the cessation of sorafenib, the serum PIVKA-II level increased abruptly (Fig. 3).

Afterward, the patient had persistent anemia with tarry stool and dizziness. In consequence, the cause of progressive anemia was suspected to be intestinal infiltration of ectopic HCC, rather than side effects of sorafenib. Because the patient refused further treatment for malignancy, he was transferred to hospice care and expired 1 year after diagnosis.

\section{Discussion}

Ectopic HCC is a rare malignancy, with morphology and immunohistochemistry similar to those of intrahepatic HCC. However, HCC development in ectopic liver is less commonly associated with risk factors for HCC arising in the mother liver, including hepatitis B virus or hepatitis $C$ virus infection, alcohol abuse, and cirrhosis [2-5], which were all absent in our case.

Ectopic HCC is difficult to diagnose at an early stage because it is typically asymptomatic before progression. Even if detected as an intra-abdominal tumor by chance, it is difficult to diagnose preoperatively because of its rarity and the difficulty of taking a biopsy specimen without operative examination. Thus, in most cases, the diagnosis is made on postoperative histopathological examinations [6]. In the present case, the diagnosis was made by histopathological examination of surgical specimens, and by serum AFP level exceeding 1,000 $\mathrm{ng} / \mathrm{ml}$ measured after pathological diagnosis. In previous reports, serum AFP levels exceeding $1,000 \mathrm{ng} / \mathrm{ml}$ were found in 20 out of 46 ectopic HCC cases (43\%), which is higher than that in 


\section{Case Reports in Gastroenterology}

Case Rep Gastroenterol 2020;14:226-233

DOI: $10.1159 / 000506929$

(c) 2020 The Author(s). Published by S. Karger AG, Base www.karger.com/crg

Ko et al.: Ectopic HCC Treated with Sorafenib

general HCC (28\%), rendering that high serum AFP levels may provide hints for the diagnosis $[1,5]$.

To fully support the diagnosis of ectopic HCC, non-cancerous liver parenchyma should be identified around the HCC [6-8]. However, non-cancerous tissue is reported in only a few cases $[2,5,9]$. Since most cases show absence of non-cancerous tissue [10], it is suspected that the malignant cells have fully expanded and replaced the ectopic liver $[5,6,10]$. Despite the fact that non-cancerous tissue was not found in our case, no HCC could be identified in the mother liver by several techniques, including sonography, CT, magnetic resonance imaging, either at the time of diagnosis or during the follow-up afterward, confirming the diagnosis of ectopic HCC.

Surgical resection of ectopic HCC is recommended, which is curative and has a favorable prognosis, because the carcinogenetic potential of these tumors is typically confined to the ectopic liver itself [7]. However, this may not apply to patients with persistent elevation of serum AFP or multiple unresectable ectopic HCC due to peritoneal dissemination $[1,7,11]$, whose clinical presentations of advanced cancer were also seen in our case.

Sorafenib, a TKI targeting tumor angiogenesis and growth, showed efficacy in the treatment of advanced HCC, which had its first clinical success in 2008, after all the trials of systemic cytotoxic therapies had failed on treating advanced liver cancer for the past decades. Sorafenib improved overall survival and time of progression in patients with advanced HCC [12]. The efficacy of sorafenib in ectopic HCC is unknown due to a rare incidence and lack of reports. In our case, although the tumor seemed to progress during sorafenib treatment, the abrupt increase in PIVKA-II level shortly after sorafenib cessation may indicate the potential effect of TKI in advanced ectopic HCC, that is, multiple unresectable lesions with peritoneal seeding. To the best of our knowledge, to date, only 1 patient has been treated with sorafenib for multiple ectopic HCC, excluding our case [13]. The patient in that case, unlike our case, has achieved progression-free survival for more than 1 year. If this patient had been able to continue sorafenib, he might have had a better prognosis with prolonged survival [14]. Currently, new kinase inhibitors such as regorafenib and lenvatinib, and human monoclonal antibody; i.e., ramucirumab, have appeared for advanced HCC, showing non-inferiority to sorafenib. More cases are required to verify the efficacy of these newly emerging regimens on ectopic HCC.

The present case demonstrates three important clinical points. First, HCC is rarely found as an intra-abdominal tumor that is defined as ectopic HCC. Second, although ectopic HCC is uncommon and difficult to be diagnosed preoperatively, high serum AFP and PIVKA-II levels might be effective for early diagnosis. Third, the effective treatment for unresectable ectopic HCC remains unknown. Additional cases should be accumulated to determine the effect of TKI on ectopic HCC.

\section{Acknowledgement}

The authors express their gratitude to Atsuko Ishibashi, Akiko Tanaka, Chihiro Tanaka, Eri Yamauchi, Motoko Kawashima, Tomoko Nagaura, Waki Nagashima, and Yuki Nozaki for the invaluable support. 


\section{Case Reports in Gastroenterology}

Case Rep Gastroenterol 2020;14:226-233

DOI: $10.1159 / 000506929$

(c) 2020 The Author(s). Published by S. Karger AG, Base www.karger.com/crg

Ko et al.: Ectopic HCC Treated with Sorafenib

\section{Statement of Ethics}

The patient has given written informed consent to publish the case, including publication of images.

\section{Disclosure Statement}

The authors have no conflicts of interest to declare.

\section{Funding Sources}

The authors have no sponsors or any funding sources to this report.

\section{Author Contributions}

All authors participated in data collection. Yi-Ling Ko and Kazuhide Takata contributed to the manuscript. All authors read and approved the final manuscript.

\section{References}

1 Huang TW, Chan DC, Lee HS, Yao NS, Lee SC, Cheng YL. Ectopic hepatocellular carcinoma of the diaphragm. Dig Dis Sci. 2007 Apr;52(4):1118-20.

2 Braun M, Kuncman W, Teresiński L, Kupnicki P, Jesionek-Kupnicka D, Kordek R. Pure hepatocellular carcinoma originates from an ectopic liver nodule located in the pancreas. Contemp Oncol (Pozn). 2017;21(4):311-4.

3 Lee JY, Kim KH, Kang MS, Kim KH. Ectopic Hepatocellular Carcinoma Arising from the Peritoneum in a Patient with a History of Oropharyngeal Cancer: A Case Report. Case Rep Oncol. 2015 Oct;8(3):456-60.

4 Arakawa M, Kimura Y, Sakata K, Kubo Y, Fukushima T, Okuda K. Propensity of ectopic liver to hepatocarcinogenesis: case reports and a review of the literature. Hepatology. 1999 Jan;29(1):57-61.

5 Kanzaki R, Yamada T, Gotoh K, Takahashi H, Ohigashi H, Ishikawa O. Ectopic Hepatocellular Carcinoma Arising in the Left Triangular Ligament of the Liver. Case Rep Gastroenterol. 2010 May;4(2):138-43.

6 Kubota K, Kita J, Rokkaku K, Iwasaki Y, Sawada T, Imura J, et al. Ectopic hepatocellular carcinoma arising from pancreas: a case report and review of the literature. World J Gastroenterol. 2007 Aug;13(31):4270-3.

7 Miyake T, Hoshino S, Yoshida Y, Aisu N, Tanimura S, Hisano S, et al. Multiple ectopic hepatocellular carcinomas arising in the abdominal cavity. Case Rep Gastroenterol. 2012 Sep;6(3):629-34.

8 Li Z, Wu X, Wen T, Li C, Peng W. Multiple ectopic hepatocellular carcinomas in the pancreas: A case report. Medicine (Baltimore). 2017 Jul;96(30):e6747.

9 Segura-Sánchez J, Torres-Domínguez Y, Ruiz-García E. Ectopic hepatocellular carcinoma in the gallbladder. Rev Esp Enferm Dig. 2014 Feb;106(2):149-50.

10 Caygill CP, Gatenby PA. Ectopic liver and hepatocarcinogenesis. Eur J Gastroenterol Hepatol. 2004 Aug;16(8):727-9.

11 Nakamura N, Irie T, Tanaka S, Arii S; N. [A case ectopic hepatocellular carcinoma with peritoneal dissemination]. Nihon Shokakibyo Gakkai Zasshi. 2013 Nov;110(11):1968-75.

12 de Rosamel L, Blanc JF. Emerging tyrosine kinase inhibitors for the treatment of hepatocellular carcinoma. Expert Opin Emerg Drugs. 2017 Jun;22(2):175-90. 


\section{Case Reports in Gastroenterology}

\begin{tabular}{l|l}
\hline Case Rep Gastroenterol 2020;14:226-233 \\
\hline DOI: 10.1159/000506929 & $\begin{array}{l}\text { @ 2020 The Author(s). Published by S. Karger AG, Basel } \\
\text { www.karger.com/crg }\end{array}$ \\
\hline
\end{tabular}

Ko et al.: Ectopic HCC Treated with Sorafenib

13 Wada Y, Takami Y, Tateishi M, Ryu T, Mikagi K, Saitsu H. The Efficacy of Continued Sorafenib Treatment after Radiologic Confirmation of Progressive Disease in Patients with Advanced Hepatocellular Carcinoma. PLoS One. 2016 Jan;11(1):e0146456.

14 Cui T, Diao X, Chen X, Huang S, Sun J. A case report: delayed high fever and maculopapules during Sorafenib treatment of ectopic hepatocellular carcinoma. BMC Cancer. 2016 Jul;16(543):543.


Fig. 1. a-c CT shows multiple contrast-enhanced tumors on arterial phase in the abdominal cavity. a The 55-mm main tumor with cystic lesions located in the lower right abdomen. b, c Multiple tumors of approximately $20 \mathrm{~mm}$ in size scattered throughout the mesentery. $\mathbf{d}$ Tumors in the abdominal cavity showing a slight increase in 18F-fluorodeoxyglucose uptake on positron emission tomography-CT image (maximum standardized uptake value: $2.88 \mathrm{~g} / \mathrm{mL}$ ). 


\section{Case Reports in Gastroenterology}
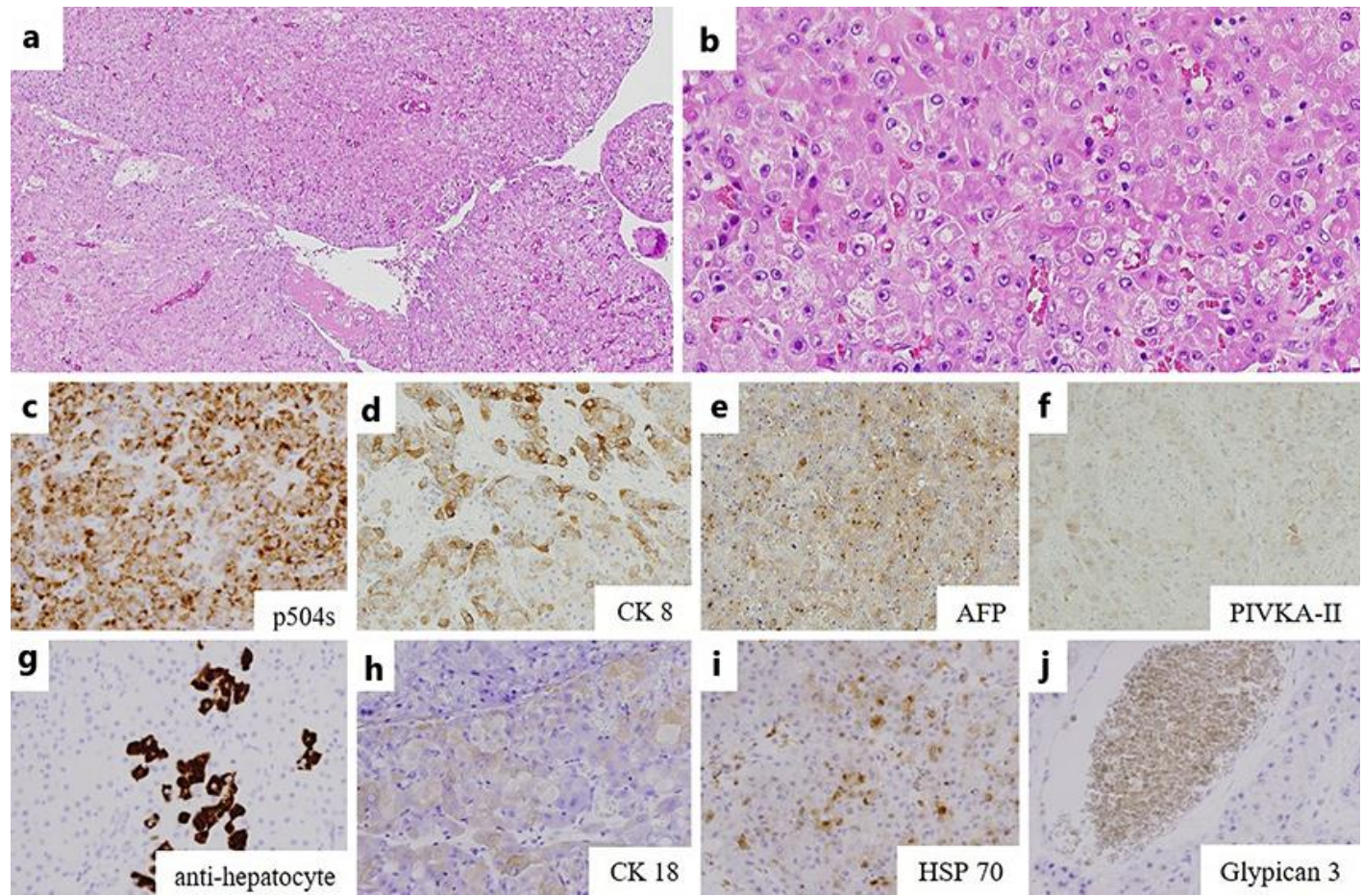

Fig. 2. Pathological findings of the peritoneal tumors were compatible with the diagnosis of ectopic HCC. a Large area of tumor cells in a trabecular pattern was revealed on HE staining, under 100 -fold magnification. $\mathbf{b}$ HE stain of the same tissue showing tumor cells with relatively abundant eosinophilic cytoplasm under 200 -fold magnification $(\times 200)$. c-f Tumor cells were positive for alpha methyl acyl coenzyme A racemase (p504s), CK 8, AFP, and PIVKA-II, respectively, on immunohistochemical staining. HE. $\times 200 . \mathbf{g}-\mathrm{j}$ Tumor cells showing weak positivity for anti-hepatocyte, CK 18, heat shock protein (HSP) 70, and glypican 3 , respectively, on immunohistochemical staining $(\times 200)$.

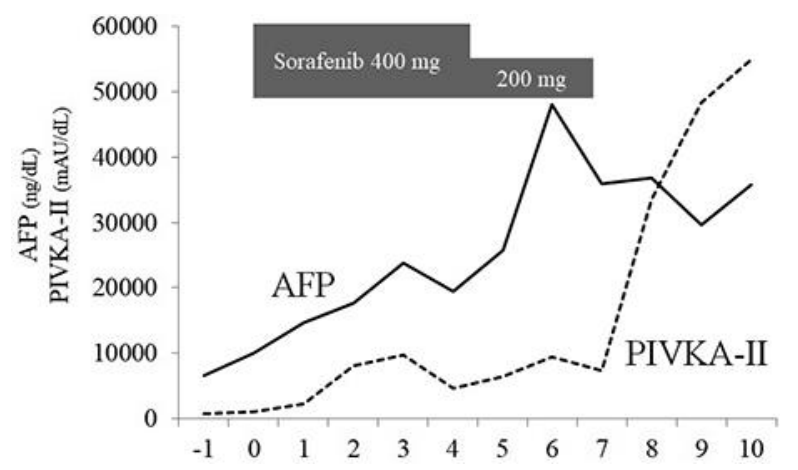

Fig. 3. Serum levels of tumor markers continued to rise despite initiation of sorafenib treatment. Sorafenib was ceased 7 months after the start of treatment. One month after the cessation, the PIVKA-II level rose abruptly. 
Ko et al.: Ectopic HCC Treated with Sorafenib

Table 1. Blood test results on admission, revealing abnormal liver enzyme levels and negative serologic tests for hepatitis B and C

\begin{tabular}{lll} 
White blood cell & 5,300 & $/ \mu \mathrm{L}$ \\
Red blood cell & 461 & $10^{4} / \mu \mathrm{L}$ \\
Hemoglobin & 14 & $\mathrm{~g} / \mathrm{dL}$ \\
Hematocrit & 40.5 & $\%$ \\
Platelet & 14.1 & $10^{4} / \mu \mathrm{L}$ \\
Total protein & 7.3 & $\mathrm{~g} / \mathrm{dL}$ \\
Albumin & 4.1 & $\mathrm{~g} / \mathrm{dL}$ \\
Total bilirubin & 0.9 & $\mathrm{mg} / \mathrm{dL}$ \\
Aspartate aminotransferase & 60 & $\mathrm{IU} / \mathrm{L}$ \\
Alanine aminotransferase & 189 & $\mathrm{IU} / \mathrm{L}$ \\
Lactate dehydrogenase & 177 & $\mathrm{IU} / \mathrm{L}$ \\
Alkaline phosphatase & 297 & $\mathrm{IU} / \mathrm{L}$ \\
Gamma-glutamyltransferase & 27 & $\mathrm{IU} / \mathrm{L}$ \\
Blood urea nitrogen & 16 & $\mathrm{mg} / \mathrm{dL}$ \\
Creatinine & 0.6 & $\mathrm{mg} / \mathrm{dL}$ \\
C-reactive protein & $<0.1$ & $\mathrm{mEq} / \mathrm{L}$ \\
Blood sugar & 235 & $\mathrm{mEq} / \mathrm{L}$ \\
Hemoglobin A1c & 9.7 & $\mathrm{U} / \mathrm{mL}$ \\
Carcinoembryonic antigen & 3.3 & $\mathrm{ng} / \mathrm{dL}$ \\
Cancer antigen 19-9 & 7 & $\mathrm{U} / \mathrm{mL}$ \\
AFP & 1,164 & $\mathrm{ng} / \mathrm{mL}$ \\
AFP isoform-L3 & 20.5 & $\%$ \\
PIVKA-II & 280 & $\mathrm{mAU} / \mathrm{mL}$ \\
Hepatitis B surface antigen & $\mathrm{Negative}$ \\
Hepatitis B core antibody & Negative & \\
Hepatitis C antibody & Negative & \\
\hline
\end{tabular}

